\title{
A REBELDIA DAS CIDADES COMO GÊNESE DA CONSTITUIÇÃO DO ESPAÇO URBANO CONTEMPORÂNEO
}

\section{CITIES' REBELLION AS A GENESIS OF CONTEMPORARY URBAN SPACE CONSTITUTION}

\author{
Maysa Mayara Costa de Oliveira* \\ José Benevides Queiroz ${ }^{* *}$
}

HARVEY, David. Cidades rebeldes: do direito à cidade à revolução urbana. Tradução Jeferson Camargo. São Paulo: Martins Fontes, 2014.

David Harvey, atualmente professor do Departamento de Antropologia da City University of New York, apesar da publicação de $A$ justiça social e a cidade, que data de 1980, ficou muito conhecido entre nós somente em 1992, quando da publicação de Condição pós-moderna, obra na qual, a partir de uma perspectiva heterodoxa do marxismo, propunha uma abordagem alternativa ao livro - de título homônimo
- de François Lyotard sobre a cultura contemporânea. Em Cidades rebeldes, fazendo jus à sua formação de geógrafo centrada na pesquisa do fenômeno urbano, Harvey retoma seu objeto de estudo principal: a cidade. Nesta obra, fruto de anos de pesquisas e que teve alguns esboços de capítulos publicados na Socialist Register e na New Left Review, busca-se mostrar a especificidade da cidade moderna, onde as relações

*Maysa Mayara Costa de Oliveira é mestranda do Programa de Pós-Graduação em Ciências Sociais da Universidade Federal do Maranhão (São Luís/MA/Brasil), graduada em sociologia pela Universidade Federal do Maranhão (UFMA). Atualmente está desenvolvendo uma pesquisa sobre a transferência dos moradores de palafitas, de São Luís/MA, para conjuntos de apartamentos construídos pelo Programa de Aceleração do Crescimento (PAC), que faz parte da política do governo federal. ysa_peppers@hotmail.com.

**José Benevides Queiroz é graduado em Ciências Sociais pela Universidade Federal do Ceará, com mestrado em Sociologia e doutorado em Ciências Sociais pela UNICAMP. É professor e pesquisador do Departamento de Sociologia e Antropologia e do Programa de Pós-Graduação em Ciências Sociais da UFMA (São Luis/MA/Brasil). malevides@yahoo.com.br. 
sociais capitalistas, principalmente a ação das classes, seus conflitos e suas disputas, moldam o espaço citadino.

Como ponto de partida, David Harvey inspira-se em duas obras do sociólogo francês Henri Lefebvre: $O$ direito $\dot{a}$ cidade e $A$ revolução urbana. Isso porque, para Lefebvre, as consequentes transformações decorrentes do processo de industrialização deram na modernidade outro caráter às cidades; diversamente, as cidades pré-industriais eram locais de criação de obras e não de produtos. Essa nova característica, de acordo com Henri Lefebvre, distingue-se na medida em que a cidade deixa de ter um valor de uso e passa a ter um valor de troca, orientando-se irreversivelmente às trocas, ao dinheiro, ao comércio e aos produtos (2001, p. 12). Com a industrialização firmase um marco na composição dos espaços e dos tipos de relações que ali se constituem. Lefebvre identifica essa mudança na predominância que as relações de troca passam a ter sobre as relações de uso, configurando agora a nova realidade urbana. Em fins da década de 1960, em $A$ revolução urbana, ao observar as diversas mudanças na paisagem de Paris e a crise existencial na qual a cidade se encontrava (a velha Paris com seu modo de vida comunitário, com cafés, praças, fontes, jardins, e a nova Paris com suas vias expressas, seus blocos de apartamentos e a desintegração dos laços comuns), ele destacou a necessidade de repensar o conceito de urbano e de buscar alternativas para um novo modo de vida que fosse voltado para as necessidades comuns.

Em Cidades rebeldes essa perspectiva é retomada por David Harvey na medida em que, para ele, o direito à cidade envolve uma luta por direitos comuns. Não por acaso, o tema que perpassa toda a obra é aquele que trata a urbanização como meio propulsor ideal ao desenvolvimento da produção de excedente de capital. 0 livro, além de tomar como referencial as duas obras de Lefebvre, tem a pretensão de dar "continuidade" às preocupações do sociólogo francês que, desde a década de 1970, ao tratar do problema urbano, já lançava questões sobre o que as cidades estavam destinadas a se tornar. Sob esta influência e referenciado em fatos históricos, Harvey expõe as diversas crises urbanas que assolaram e ainda fustigam indistintamente as grandes e as pequenas cidades, bem como, e principalmente, o ressurgimento da discussão a respeito do direito à cidade através das mobilizações dos movimentos urbanos difusos por todo o mundo.

Dividido em duas partes, Cidades rebeldes apresenta na primeira uma espécie de dossiê, no qual Harvey destaca os diversos casos de crises e escândalos que envolvem os booms imobiliários atrelados ao modo de urbanização que ocorre em escala global, as crises geradas pela grande especulação f1nanceira e as altas taxas de juros decorrentes do capital fictício. Todos esses três aspectos são abordados levando em consideração a extensão em que afetam a vida urbana. A segunda parte dedica-se aos exemplos de reivindicações de vários movimentos de diversas regiões do globo, apontando a necessidade de que os habitantes das cidades participem das lutas e articulações políticas, para que a ocupação dos espaços de fato parta de iniciativas coletivas. Neste ponto, ele destaca o caso da Bolívia, pelo modo como a articulação da população de Cochabamba e El Alto, por meio da associação de pessoas, conseguiu superar as dificuldades e adversidades que são impostas à vida cotidiana daquelas distintas localidades.

Já no primeiro capítulo, denominado " 0 direito à cidade", Harvey, com o intuito de 
elucidar a natureza desse direito, discute as circunstâncias de como se processa o atual fenômeno da urbanização, destacando o papel primordial do mercado imobiliário para os Estados Unidos e também para os projetos urbanos de outras partes do mundo, como por exemplo os da China e da Índia. Além disso, o autor retoma discussões sobre alguns pontos referentes à obra de Karl Marx, tentando mostrar como sua teoria pode ainda contribuir para a compreensão do argumento central de seu livro, particularmente aquele que diz respeito ao papel que a urbanização tem desempenhado para a absorção de mercadorias excedentes. É o caso novamente dos Estados Unidos, como destaca, pois seu processo de suburbanização, após o período da Segunda Guerra, não foi apenas infraestrutural, mas implicou a transformação de um estilo de vida com a inserção de novos produtos, como casas pré-fabricadas e a introdução de outros bens duráveis nos subúrbios: aparelhos de ar condicionado, geladeiras e carros, ou seja, novas "necessidades" que contribuíram para absorver o excedente de capital decorrente do período pós-guerra (p. 38). Ao mesmo tempo, como contraponto, ele chama atenção para o fato de que a urbanização passa a ser um processo que ocorre em escala global, sendo assim necessário não centrar-se exclusivamente na análise do caso americano. Nesse sentido, a análise do processo de urbanização em escala global significa, de acordo com Harvey, uma assombrosa integração dos mercados financeiros, que usam sua flexibilidade para financiar projetos em diversas partes do mundo (p. 41).

A urbanização como algo resultante da produção de excedentes transformou também a qualidade de vida em uma mercadoria. Projetos urbanísticos que prometem um estilo de vida voltado para o consumo, em que locais como shopping centers, restaurantes, bares, cafés, centros comerciais, condomínios fechados etc. significam cada vez mais a divisão da cidade em partes distintas: a dos que podem pagar e ter acesso a todos os tipos de serviços e a dos que são cada vez mais subjugados a esse tipo de urbanização, sem direito aos serviços de saneamento e passiveis de casos de desapropriação, o que é destacado e defınido por Harvey como "destruição criativa” (p. 47-48).

Fazendo uma análise mais estrutural a respeito das crises capitalistas em decorrência das bolhas imobiliárias, tanto nos Estados Unidos como em outras partes do mundo, Harvey, no segundo capítulo "As raizes urbanas das crises capitalistas”, destaca o papel do Banco Mundial como um grande favorecedor do capital especulativo. 0 autor lança críticas às teorias dos consultores do Banco Mundial por desconsiderarem que a maioria das centenas de crises, principalmente no período de 1973 a 2000, está relacionada ao desenvolvimento imobiliário e urbano (p. 71). No mesmo sentido, ele critica tanto a teoria econômica sistêmica, de extração burguesa, pois que essa desconsidera e não relaciona o desenvolvimento urbano com os desarranjos macroeconômicos, como os teóricos marxistas, uma vez que deixam de lado os fenômenos do aumento dos aluguéis e dos processos de desapropriação (p. 81). Ainda em dissonância com estes últimos teóricos, o autor levanta alguns pontos de discussão a respeito de como a abordagem de Marx sobre as leis gerais de circulação do capital mantém sua importância para a compreensão do momento atual. Assim, as análises de Marx desmontariam o "discurso" do capital fictício na medida em que ele considera que este capital é um fenômeno superficial 
que mascara algo importante nas relações sociais (p. 88). A partir desse referencial, Harvey denuncia as formas predatórias de taxação de juros e os esquemas de pirâmides, entre outras formas fraudulentas como o mercado imobiliário americano atuou e vem atuando, e que geraram grandes crises financeiras, pois o enorme crescimento da demanda não possibilitou que houvesse o mesmo crescimento da oferta, contradizendo o argumento de um "livre funcionamento do mercado".

Segundo Harvey, outro aspecto revelador dos esquemas fraudulentos do mercado imobiliário americano é evidenciado na guerra de classe desencadeada pela crise urbana. Os preconceitos de classe e raça expressos pelo sistema financeiro são explícitos, visto que é na população afro-americana de baixa renda que se concentra o maior percentual de perdas de ativos, cerca de 71 a 93 bilhões dólares, decorrentes de práticas imobiliárias predatórias. Como consequência disso, ressalta ele, ocorreram fortes processos de desapropriações de imóveis, que chegaram em duas ondas: uma no período de 1995 a 1998 e a outra depois de 2001 (p. 113).

Para contrapor-se à forma de pensar a cidade e a urbanização como categorias atreladas aos investimentos privados, Harvey discute o conceito de "comum" destacando a citação de Garret Hardin, em $A$ tragédia dos comuns, e opondo-se às suas argumentações para destacar as diferenças entre os bens públicos e os espaços públicos. A discussão centra-se em torno de uma reflexão sobre a cidade como um lugar comum em meio aos interesses do capital privado. Sendo assim, para enfrentar os problemas já destacados no livro, em decorrência da influência desse capital financeiro nos projetos urbanísticos, ele mostra o quão importante é romper com as amarras de pensar a propriedade, a cidade e o espaço urbano como algo privado (p. 135-136). Além disso, destaca a dominação do capitalismo sobre as culturas locais analisando a renda de monopólio atrelada à lógica da acumulação de capital, por meio da qual este tem mecanismos para extrair excedentes a partir das diferenças e das variações dessas culturas, exemplificados pelos tipos de turismo realizados em periferias como o Harlem, em Nova York, ou as favelas do Rio de Janeiro, da África do Sul ou de Mumbai (p. 202). Mesmo assim, Harvey chama atenção para a importância que a cultura popular tem na produção de relações comuns na vida cotidiana, na construção de espaços alternativos contra os efeitos globalizantes, e na fundamentação de uma política de antimercantilização.

Como alternativa ou possível movimento de oposição aos efeitos da dominação dos interesses privados na construção dos espaços citadinos, o autor, na segunda parte do livro, discute a forma que poderia tomar a luta em relação ao direito à cidade. Nesse aspecto, Harvey chama atenção para a constituição do espaço urbano como um espaço de crucial importância para a ação política. Isso pode ser observado pelo histórico dos movimentos revolucionários em Paris, desde 1789 até a Comuna em 1871, e, posteriormente, em várias partes do mundo, como Xangai, Seattle, Barcelona (na Guerra Civil Espanhola), nas insurreições urbanas dos Estados Unidos, na década de 1960, e nos recentes protestos em Madri, Atenas, Cidade do México, Cochabamba e El Alto, Buenos Aires, Santiago etc. (p. 209-210). Além de sua importância para a ação política, como destaca o autor, nesses espaços os movimentos reivindicatórios têm igualmente a capacidade de exercerem 
uma forte influência sobre a dinâmica da economia urbana.

Essa abrangência dos movimentos reivindicatórios no espaço urbano, pois que influencia esse espaço diretamente tanto na sua dimensão física quanto na econômica, exige uma redefınição do conceito de proletariado, segundo Harvey. Primeiro, porque o conceito foi cunhado quando do advento da revolução industrial para identificar um segmento social - destituído de meios de vida e de produção - vinculado à produção do capital. Segundo, em razão de o proletariado sempre ser considerado como vanguarda dos movimentos da classe operária e expressão do conjunto dos trabalhadores fabris. Terceiro, porque não é mais plausível pensarmos na existência de um grande proletariado fabril, uma vez que hoje ele foi radicalmente reduzido em termos de número. Na nova concepção que propõe Harvey, o grosso do proletariado encontra-se distante do processo produtivo em si; ele agora deve ser considerado "proletariado urbano", pois sua luta volta-se então para ter o direito de controlar a cidade que ajuda maciçamente a construir (p. 232).

A partir dessa redefinição, para exemplificar como os atuais movimentos anticapitalistas se orientam e agem, o autor menciona o caso da organização das mobilizações na Bolívia, mais especificamente nas cidades de Cochabamba e El Alto. Os dois casos expressam um forte sentimento de solidariedade, baseados na associação de pessoas e lugares, mostrando como são importantes os laços comuns. Nesse sentido, as lutas de El Alto, como qualquer outra luta anticapitalista, necessitam que sua consolidação seja vista com certo nível de generalidade, o que explica Harvey voltar suas preocupações para a busca de coerência dos movimentos urbanos que possuem suas pautas especificas.
Isso faz com que o autor tenha uma forte convicção de que a forma de reestabelecer regras para a redistribuição da riqueza entre as cidades deve ocorrer através do consenso democrático entre os sujeitos coletivos dotados de poder decisório (p. 265). Não por acaso, em outra publicação recente, o autor mostra como isso ocorreu no Brasil, no caso do Orçamento Participativo, particularmente na experiência que se desenvolveu nos últimos anos em Porto Alegre (HARVEY, 2013); dentro da mesma perspectiva, poderíamos ainda citar mais dois exemplos brasileiros atuais: as iniciativas locais por parte de associação de moradores para revitalização/ apropriação de espaços públicos, como a Associação dos Amigos do Parque Minhocão em São Paulo, que visa transformar o antigo viaduto em parque, e, na cidade de Recife, o movimento Ocupe Estelita (BUENO, 2014) que, desde 2012, vem lutando contra as modificações propostas pela especulação imobiliária da área do Cais José Estelita.

Para além da periferia do capitalismo globalizado, Harvey destaca, como exemplos das alternativas de enfrentamento, dois marcantes momentos dos embates dos movimentos urbanos contestatórios. 0 primeiro em Londres, no ano de 2011, em que analisa o momento de total insustentabilidade do sistema capitalista ao denominá-lo de "feroz". Tal denominação justifıca-se na medida em que não há mais condições para que os moradores das cidades arquem com os gastos do dinheiro público em fraudes, investimentos em empresas privadas, operadores de custos de risco, e companhias que manipulam e detêm o dinheiro público, "mandam e desmandam" no que será investido na cidade, contradizendo sempre as necessidades da maioria de seus habitantes (p. 274). 0 ápice disso, como segundo momento, ocorre nos Estados Unidos por 
meio do "Partido de Wall Street", que tem capacidade de dominar políticos, meios de comunicação, e também grande parte do aparato judiciário, em especial a Suprema Corte. 0 movimento "Occupy Wall Street" coloca-se como forma de enfrentamento da população cansada dos ditames do poder instaurador da classe capitalista, reivindicando um sistema político alternativo que visa organizar a produção, a distribuição e o consumo em benefício da população (p. 282). Em sintese: esses movimentos, embora pareçam não tratar de imediato do espaço urbano, ocorrem e se desenvolvem no interior das cidades afetando-as de modo marcante na sua estrutura física, organizacional e de funcionamento.

A partir do exposto, pode-se afirmar que Cidades rebeldes é a atualização das questões tratadas na década de 1960 por Henri Lefebvre, só que em um novo patamar. Enquanto o sociólogo francês mostrava como a ideologia do consumo repercutia no dia a dia das cidades implicando num determinado tipo de urbanismo, Harvey destaca o tipo globalizante de urbanização atrelado ao capital financeiro e com consequências devastadoras no modo de vida urbano. Ao mesmo tempo, como o sociólogo francês, seus estudos mostram que, em reação ao poder do capital, inúmeros movimentos sociais urbanos são capazes de influir na dinâmica ou apontar alternativas que satisfaçam aos interesses das comunidades citadinas; ou seja, são esses movimentos, tendo à frente o proletariado urbano, que podem conquistar e garantir - lutando e exercendo o controle coletivo sobre a produção, principalmente do espaço urbano - o direito à cidade. Por isso Harvey conclui que hoje, mais do que na época de Lefebvre, "a revolução tem de ser urbana”, pois as atuais e repetidas crises ocorrem no interior desse espaço ou decorrem da sua reprodução, e por isso fazem dele o verdadeiro ponto de confronto.

\section{Referências}

BUENO, C. Ocupe Estelita: movimento social e cultural defende marco histórico de Recife. Revista Ciência e Cultura, vol. 66, nº 4, São Paulo, p. 5 - 6. out/dez. 2014.

HARVEY, D. A liberdade da cidade. In: MARICATO, E. [et al.]. Cidades rebeldes: passe livre e as manifestações que tomaram as ruas do Brasil. São Paulo: Boitempo/Carta Maior, p. 47 - 61. 2013.

A justiça social e a cidade, São Paulo: Hucitec, 1980.

Condição pós-moderna, São Paulo: Edições Loyola, 1992.

. 0 direito à cidade. Revista Piauí, n. 82, p. 1 - 11. jul. 2013.

LEFEBVRE, H. A revolução urbana. Belo Horizonte: Ed. UFMG, 2008. 3ª reimpressão.

0 direito a cidade. Tradução Rubens Eduardo Frias. 5. ed. São Paulo: Centauro, 2011. 3a reimpressão.

Recebido em: 03/11/15

Aprovado em: 15/12/15 